\title{
Child injury surveillance capabilities in NSW: informing policy and practice
}

\section{Rebecca Mitchella,b and Luke Testaa}

a Australian Institute of Health Innovation, Macquarie University, Sydney, NSW

b Corresponding author: r.mitchell@mq.edu.au

\section{Article history}

Publication date: October 2017

Citation: Mitchell R, Testa L. Child injury surveillance capabilities in NSW: informing policy and practice. Public Health Res

Pract. 2017;27(4):e2741734.

https://doi.org/10.17061/phrp2741734

\section{Key points}

- Good-quality information from injury surveillance is important for the development of injury prevention policies

- None of the data collections examined were ideal for conducting injury surveillance of children and young people

- Better coordination and reporting of injury information across agencies is needed to report on and monitor childhood injury, including use of linked data collections

\begin{abstract}
Injury is one of the most common reasons why a child is hospitalised. Information gained from injury surveillance activities provides an estimate of the injury burden, describes injury event circumstances, can be used to monitor injury trends over time, and is used to design and evaluate injury prevention activities. This perspective article provides an overview of child injury surveillance capabilities within New South Wales (NSW), Australia, following a stocktake of population-based injury-related data collections using the Evaluation Framework for Injury Surveillance Systems.

Information about childhood injury in NSW is obtained from multiple administrative data collections that were not specifically designed to conduct injury surveillance. Obtaining good information for child injury surveillance in NSW will involve better coordination of information from agencies that record information about childhood injury. Regular reporting about childhood injury to provide a comprehensive profile of injuries of children and young people in the state should be considered, along with the provision and/or linkage of child injury information from multiple data collections. This could support the development of a suite of injury performance indicators to monitor childhood injury reduction strategies across NSW.
\end{abstract}

\section{Background}

Childhood injury represents a considerable public health burden in Australia, with 58997 hospital admissions of children aged less than 15 years in 2012-13 following an injury ${ }^{1}$, representing an estimated $1.3 \%$ of the population aged younger than $15 .{ }^{2}$ Information about childhood injuries is obtained from injury surveillance activities. Injury surveillance involves the ongoing, systematic collection, analysis and interpretation of data essential to the prevention, planning and evaluation of public health practice, with the timely dissemination of these data and their application to prevention and control. ${ }^{3}$

The World Health Organization (WHO) has developed guidelines for conducting injury surveillance ${ }^{4}$ and has recommended core and optional minimum data to be collected to conduct injury surveillance. These core and optional minimum data can also be supplemented with additional data pertinent to specific injury mechanisms, such as vehicle crashes. An 
Evaluation Framework for Injury Surveillance Systems (EFISS) ${ }^{5}$ has also been developed to assess the overall ability of a data collection to conduct injury surveillance. There are three main components of the EFISS, which assess: 1) data quality, 2) operational ability, and 3) practical characteristics of a data collection to perform injury surveillance. This perspective article provides an overview of child injury surveillance capabilities in New South Wales (NSW), Australia.

\section{Stocktake of data sources in NSW}

Within NSW, population-level information about injuries is obtained from multiple data collections, such as emergency department presentations, hospital admission records, police records or insurance claims. However, each of these data collections is largely designed to fulfil administrative functions such as service monitoring or resource allocation, rather than to perform injury surveillance. Therefore, the information obtained may not always be ideal for surveillance purposes (i.e. to describe what injuries occurred to whom, in which location, when they occurred and why $\left.{ }^{5,6}\right)$. In some data collections, the information recorded for some data variables is not as complete as it could be - for example, within hospitalisation data, the location and activity of the person at the time of an injury is often recorded as 'other or unspecified'.

In NSW, a recent stocktake conducted for NSW Kids and Families identified data collections that could provide information about childhood injury at a population level. Each data collection was reviewed using the EFISS for its ability to perform injury surveillance. ${ }^{6}$ Only two EFISS characteristics - operational ability (such as timeliness and quality control measures) and practical characteristics (such as accessibility and available guidance material to aid interpretation) - were examined for the stocktake. The stocktake identified three mortality and 13 injury morbidity and/or mortality population-based data collections that could report on injuries involving children and young people in NSW (Box 1).

The stocktake identified that none of the data collections examined were ideal to conduct injury surveillance of children and young people, as no data collection (except for the National Coronial Information System) could effectively capture all the information recommended by WHO for injury surveillance. Nor was there a central data warehouse where injury-related data collections could be easily accessed to conduct injury surveillance. Instead, information about childhood injury in NSW is accessed using a range of either national or NSW-based data collections that are warehoused by different agencies. No single data collection could provide information across the injury continuum (i.e. from identifying injury risk factors to describing the injury event circumstances, to providing information about
Box 1. Population-based data collections that can provide information about injuries involving children and young people in NSW

\section{Injury mortality data collections}

- Cause of death unit record file

- Child deaths register

- National Coronial Information System

Injury morbidity and/or mortality data collections

- NSW Ambulance clinical record

- NSW Admitted Patient Data Collection

- NSW Emergency Department Data Collection

- NSW Key Information and Directory System (Department of Family and Community Services)

- NSW Lifetime Care claims database

- NSW Personal Injury Register (State Insurance Regulatory Authority)

- NSW Public Health Real-time Emergency Department Surveillance System

- NSW sporting injuries claims data

- Surfguard database

- CrashLink

- NSW Trauma Registry

- NSW workers' compensation data

the injuries sustained and their treatment, to monitoring injury outcomes).

None of the data collections examined had the ability to readily identify new mechanisms of childhood injury. One specific gap was the inability to identify injuries associated with new products. The identification of injuries to children and young people using child quad bikes ${ }^{7}$ and poisoning via gamma-hydroxybutyrate following ingestion of Bindeez beads ${ }^{8}$ required the vigilance of emergency department clinicians, rather than systemic identification of these injury incidents through surveillance mechanisms. It may be that new product-related injuries will always rely on notification by clinicians because routine surveillance of emerging types of injuries is not easily recognised by current injury surveillance systems.

\section{Improving child injury surveillance capabilities}

For some types of injuries and/or injury mechanisms, there is potential to add value to the information available for injury surveillance and research activities by linking data collections that record information about different stages of the injury continuum. ${ }^{9}$ By linking information 
from multiple cross-sectoral data collections that record information about the same injury event, a rich data source can be created for use in child injury surveillance and research activities.

The added value of linking information from different data collections can be illustrated for road trauma. Hospital admission data collections provide detailed information about the injuries experienced and treatment received, but only limited information about the circumstances of the crash (e.g. road conditions or infrastructure) and crash risk factors (e.g. vehicle speed or driver fatigue) or injury risk factors (e.g. restraint or helmet use) - all information contained in police crash data. However, police crash data contain no information about types of injuries sustained. Research that used linked hospitalisation and police-reported crash data for NSW was able to examine the effectiveness of bicycle helmets in reducing severe head injury in bicycle-vehicle collisions and demonstrated a reduction in head injury severity with helmet use. ${ }^{10}$ Linked NSW hospitalisation and road crash data were also used to examine the injury severity of front- and rear-seated vehicle occupants injured in the same vehicle and was able to identify that rear-seat occupants sustained injuries of higher severity than front-seat car occupants, particularly in newer vehicles with airbags, implying that protective measures for rear-seat occupants need improvement. ${ }^{11}$

Information from injury surveillance activities is regularly used to inform the development of injury prevention strategies and to evaluate the impact of these strategies on the population. ${ }^{10,11}$ Information from injury surveillance activities is also used to estimate the burden of different types of injuries, describe the circumstances of injury events, and monitor temporal injury trends. ${ }^{12-14}$ The development of injury prevention strategies and evaluation of injury prevention policy relies on having good-quality and timely information available from injury surveillance activities. ${ }^{12}$ It is crucial that the best available information is used to inform and evaluate childhood injury prevention policies in NSW.

The provision of good information for child injury surveillance in NSW will need to involve better coordination of information from agencies that record information about childhood injury. Consideration should also be given to regular reporting of childhood injury using all available injury data collections, to provide a comprehensive profile of injuries among children and young people in the state. Provision and/or routine linkage of information about child injury from a number of data collections, overseen by different agencies, would allow for the development of a suite of injury performance indicators to monitor childhood injury reduction strategies across NSW.

\section{Acknowledgements}

The authors wish to thank the data custodians and/ or managers who provided information about data collections. This research was funded by NSW Kids and Families, NSW Health. The research conclusions are those of the authors and any views expressed are not necessarily those of the funding agency.

\section{Competing interests}

None declared

\section{Author contributions}

RM wrote the first draft of the manuscript. RM and LT were both involved in the critical revision of the manuscript.

\section{References}

1. Pointer S. Trends in hospitalised injury, Australia 1999-00 to 2012-13. Canberra: Australian Institute of Health and Welfare; 2015 [cited 2017 Aug 15]. Available from: apo.org.au/system/files/56883/apo-nid56883-149746.pdf

2. Australian Bureau of Statistics. Canberra: ABS; 2017. Australian demographic statistics, Dec 2016 [updated 2017 Jun 26]; [cited 2017 Aug 15]; [about 3 screens]. Available from: www.abs.gov.au/ausstats/abs@.nsf/mf/3101.0

3. Thacker SB, Berkelman RL. Public health surveillance in the United States. Epidemiol Rev. 1988;10:164-90.

4. World Health Organization. Injury surveillance guidelines. Geneva: WHO; 2001 [cited 2017 Aug 15]. Available from: apps.who.int/iris/bitstream/10665/42451/1/9241591331. pdf

5. Mitchell RJ, Williamson AM, O'Connor R. Development of an evaluation framework for injury surveillance systems. BMC Public Health. 2009;9:260

6. Mitchell R, Testa L. Stocktake of data sources for childhood injury in NSW. Sydney: NSW Health, Macquarie University; 2015.

7. Mitchell R. Quad bike-related fatal and non-fatal injuries: examination of injury patterns and crash circumstances. In: Grzebieta R, Rechnitzer G, Mclntosh A, Mitchell R, Patton D, Simmons K. Investigation and analysis of quad bike and side by side vehicle (SSV) fatalities and injuries. Sydney: UNSW, Transport and Road Safety Research; 2015 [cited 2017 Aug 17]. Available from: www.tars.unsw.edu.au/research/Current/Quad-Bike_ Safety/Reports/Supplemental_Report_Exam\&Analysis_ Fatals\&Injuries_Jan-2015.pdf 
8. McDonald K. Lab+Life Scientist; 2017. How the Bindeez were busted; 2008 Jan 25 [cited 2017 Aug 15]; [about 8 screens]. Available from: www.labonline.com. $\mathrm{au} / \mathrm{content/life-scientist/article/how-the-bindeez-were-}$ busted-1330752481

9. Mitchell R, Cameron C, Bambach M. Data linkage for injury surveillance and research in Australia: perils, pitfalls and potential. Aust N Z J Public Health. 2014;38(3):276-81.

10. Bambach M, Mitchell R, Grzebieta R, Oliver J. The effectiveness of helmets in bicycle collisions with motor vehicles: a case-control study. Accid Anal Prev. 2013;53:78-88.
11. Mitchell R, Bambach M, Toson B. Injury risk for matched front and rear seat car passengers by injury severity: an exploratory study. Accid Anal Prev. 2015;82:171-9.

12. Mitchell R, McClure R, Williamson A, McKenzie K. Implementing the national priorities for injury surveillance. Med J Aust. 2008;188(7):405-8.

13. Langley $\mathrm{J}$. The role of surveillance in reducing morbidity and mortality from injuries. MMWR Morb Mortal Wkly Rep. 1992;41(Suppl):181-91.

14. Harrison J, Tyson D. Injury surveillance in Australia. Acta Paediatr Jpn. 1993;35(3):171-8.

\section{Copyright: (c) (i) (2)}

(c) 2017 Mitchell and Testa. This article is licensed under the Creative Commons Attribution-NonCommercial-ShareAlike 4.0 International Licence, which allows others to redistribute, adapt and share this work non-commercially provided they attribute the work and any adapted version of it is distributed under the same Creative Commons licence terms. See: www.creativecommons.org/licenses/by-nc-sa/4.0/ 